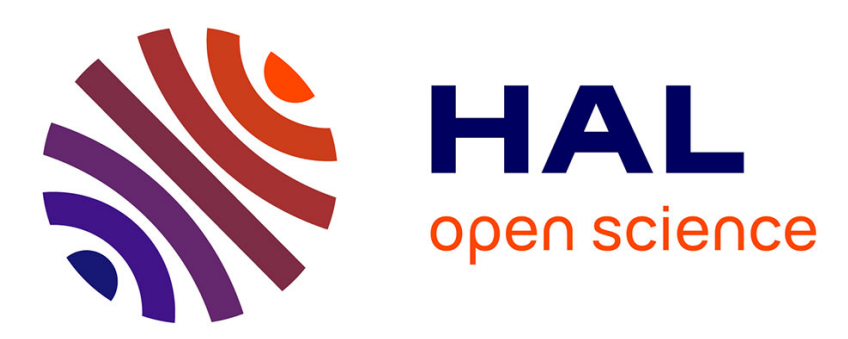

\title{
Adverse reactions to patent blue V dye - The New Start and Almanac experience
}

\author{
L. Barthelmes, A. Goyal, R.G. Newcombe, F. Mcneill, R.E. Mansel
}

\section{To cite this version:}

L. Barthelmes, A. Goyal, R.G. Newcombe, F. Mcneill, R.E. Mansel. Adverse reactions to patent blue V dye - The New Start and Almanac experience. EJSO - European Journal of Surgical Oncology, 2010, 36 (4), pp.399. 10.1016/j.ejso.2009.10.007 . hal-00576172

\section{HAL Id: hal-00576172}

\section{https://hal.science/hal-00576172}

Submitted on 13 Mar 2011

HAL is a multi-disciplinary open access archive for the deposit and dissemination of scientific research documents, whether they are published or not. The documents may come from teaching and research institutions in France or abroad, or from public or private research centers.
L'archive ouverte pluridisciplinaire HAL, est destinée au dépôt et à la diffusion de documents scientifiques de niveau recherche, publiés ou non, émanant des établissements d'enseignement et de recherche français ou étrangers, des laboratoires publics ou privés. 


\section{Accepted Manuscript}

Title: Adverse reactions to patent blue $V$ dye - The New Start and Almanac experience

Authors: L. Barthelmes, A. Goyal, R.G. Newcombe, F. McNeill, R.E. Mansel

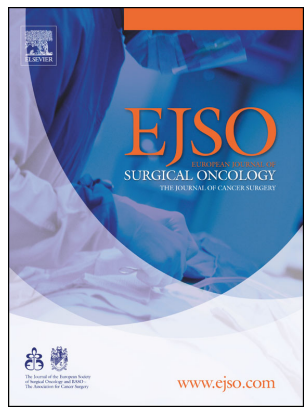

PII:

S0748-7983(09)00479-X

DOI:

10.1016/j.ejso.2009.10.007

Reference: $\quad$ YEJSO 2901

To appear in: European Journal of Surgical Oncology

Received Date: 23 July 2009

Revised Date: 14August2009

Accepted Date: 8 October 2009

Please cite this article as: Barthelmes L, Goyal A, Newcombe RG, McNeill F, Mansel RE. Adverse reactions to patent blue $V$ dye - The New Start and Almanac experience, European Journal of Surgical Oncology (2009), doi: 10.1016/j.ejso.2009.10.007

This is a PDF file of an unedited manuscript that has been accepted for publication. As a service to our customers we are providing this early version of the manuscript. The manuscript will undergo copyediting, typesetting, and review of the resulting proof before it is published in its final form. Please note that during the production process errors may be discovered which could affect the content, and all legal disclaimers that apply to the journal pertain. 
Adverse reactions to patent blue $V$ dye - The NEW START and ALMANAC experience

Authors: L Barthelmes ${ }^{\mathrm{a}}$, A Goyal ${ }^{\mathrm{a}}$, RG Newcombe ${ }^{\mathrm{b}}, \mathrm{F}$ McNeill $^{\mathrm{c}}$, RE Mansel $^{\mathrm{a}}$ on behalf of the NEW START and ALMANAC study groups.

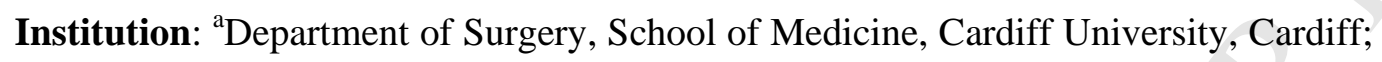

${ }^{\mathrm{b}}$ Department of Epidemiology, Statistics and Public Health, School of Medicine, Cardiff University, Cardiff; ' Department of Surgery, Royal Marsden Hospital, London.

\section{Address for Correspondence:}

Robert E Mansel, Department of Surgery, School of Medicine, Cardiff University, Cardiff, CF14 4XN, United Kingdom

Tel: +44(0)29 2074 2749, Fax: +44(0)29 20742896

Email: manselre@cf.ac.uk

Category: Original article

Conflict of interest: None

Key words: anaphylaxis, allergy, breast cancer, sentinel lymph node biopsy, patent blue $\mathrm{V}$, isosulfan blue 


\section{Abstract \\ Background}

Blue dye with or without isotope has been widely used to identify the sentinel lymph node(s) in breast cancer. Patent blue V is used in the UK while its isomer isosulfan blue is used in the US. The allergic potential of isosulfan blue is well documented (1.4\% adverse reactions) but that of patent blue $\mathrm{V}$ is less clearly defined.

\section{Methods}

In this paper we review the adverse reactions of patent blue $\mathrm{V}$ in 7,917 patients participating in the NEW START training programme and the ALMANAC trial. All patients underwent sentinel lymph node biopsy for breast carcinoma using patent blue $\mathrm{V}$ in combination with ${ }^{99 \mathrm{~m}} \mathrm{Tc}$-albumin colloid.

\section{Results}

In total, 72 of 7,917 (0.9\%) patients experienced adverse reactions : non-allergic reactions were observed in $4(0.05 \%)$ patients, $23(0.3 \%)$ patients had minor grade I allergic skin reactions (urticaria, blue hives, pruritis, or generalised rash) and 16 (0.2\%) had grade II reactions (transient hypotension/ bronchospasm /laryngospasm). Severe Grade III reactions (severe hypotension requiring vasopressor support and/or and/or change / abandoning of planned procedure and/or HDU/ITU admission) were noted in $5(0.06 \%)$. The type of adverse reaction was not specified in $24(0.3 \%)$ patients. No mortality was recorded.

\section{Conclusion}

The allergic potential of patent blue V dye compares favourably with isosulfan blue however both surgeon and anaesthetist need to be alert to the risk of allergic reactions. 


\section{Introduction}

Patent blue V dye has been used since the 1960's in lymphangiography. It is a 2,5 disulfonated calcium-chelated dimer of the triphenylmethane family (CAS number 3536-49-0). ${ }^{1}$ Outside medicine it is used in textiles and as a food colourant (E 131) and potentially exposes the general population to the risk of allergic sensitisation. ${ }^{2}$ With its use in sentinel lymph node biopsy there is a renewed interest in its medical role. We reviewed our experience of its allergic potential in the large number of patients in the NEW START training programme and the ALMANAC trial. In addition, we searched the ADROITE database of the Committee of Safety of Medicines and the pharmacovigilance files of the manufacturer (Laboratoire Guerbet, Aulnay-Sous-Bois, France) and compared the rate of adverse effects of patent blue V with other dyes, namely isosulfan and methylene blue. 


\section{Patients and Methods}

Before implementing sentinel lymph node biopsy (SLNB) for axillary nodal staging we investigated the procedure in a multicentre, randomised study (ALMANAC randomised controlled trial) ${ }^{3}$ preceded by a validation phase. We have now rolled out a UK - wide sentinel lymph node biopsy training programme (NEW START) in the UK to train breast teams and at the same time ensure patient safety.

Blue dye injection technique

In the ALMANAC validation phase and the ALMANAC randomised trial $2 \mathrm{ml}$ of 2.5\% aqueous solution of patent blue $\mathrm{V}$ diluted to $5 \mathrm{ml}$ with normal saline was injected around the tumour. In the NEW START sentinel lymph node training programme undiluted $2 \mathrm{ml}$ of $2.5 \%$ patent blue $\mathrm{V}$ dye or $2 \mathrm{ml}$ of $2.5 \%$ aqueous solution of patent blue $\mathrm{V}$ diluted to $5 \mathrm{ml}$ with normal saline was injected subdermally at the areola-skin margin of the index quadrant.

\section{Adverse reactions}

Side-effects after injection of patent blue $\mathrm{V}$ dye injection were recorded prospectively. The participating surgeons described the specific reaction in a free-text box. Drug treatment of the reaction (histamine antagonist, steroids or vasopressor use), admission to intensive care unit or changes of procedure were recorded. The classification of blue dye allergic reactions described by Montgomery et al. ${ }^{4}$ was modified and used in this study. Allergic reactions were defined as grade I (urticaria, blue hives, pruritis or generalised rash), grade II (transient hypotension/bronchospasm/laryngospasm), grade III (severe hypotension requiring vasopressor support and/or change/abandoning of planned procedure and/or HDU/ITU admission) and grade IV (cardiorespiratory arrest and/or death). 


\section{Results}

\section{Adverse reactions}

9 of 839 patients in the ALMANAC validation phase, 5 of 492 patients in the ALMANAC randomised trial, and 58 of 6586 patients in the NEW START training programme were noted to have an adverse reaction to patent blue V dye. In total, 72 of 7917 (0.9 \%) patients experienced adverse reactions (Table 1).

23 patients experienced minor (grade I) allergic skin reactions. Grade II allergic reactions occurred in 16 patients. 5 patients experienced severe grade III allergic reactions (Table 2).

Non-allergic reactions were observed in 4 patients. The type of adverse reaction was not specified in 24 patients. Drug treatment for grade 1 and grade 2 reactions included administration of a histamine antagonist and/or hydrocortisone. 2 of 5 patients with grade 3 reaction were admitted to HDU/ITU for observation but recovered without any sequelae. In one patient who developed severe hypotension immediately after administration of patent blue $\mathrm{V}$ the procedure was abandoned. The planned operative procedure had to be changed in two patients with grade 3 reactions. All patients recovered from their reactions without any long-term morbidity. There was no mortality.

\section{Committee of the Safety of Medicines - Yellow Card Scheme}

We searched the database of the Committee of the Safety of Medicines (Yellow Card Scheme in UK) for adverse reactions following the use of patent blue V. Between 7.1.1974 to 15.4 .2008 there were 46 reports of 97 reactions, nearly half of them (44 / 97) due to anaphylactic immune system and skin disorders. There was one cardiorespiratory arrest, but no mortality. 
Manufacturer records

Pharmacovigilance files of the manufacturer revealed 86 cases (collated worldwide, including cases reported in literature) corresponding to 158 adverse events between 1/5/2002 to 30/4/2007. As 780,705 doses were sold during the period, the reporting frequency is estimated at 11 cases per 100,000 patients and 2 adverse events for 10,000 patients (personal communication Dr. Sophie Gaillard - Guerbet).

Isosulfan blue

Several American studies have addressed the issue of allergic reactions following injection of isosulfan, an isomer of patent blue V, for sentinel lymph node biopsy in breast and melanoma patients (Table 3). Adding all studies, $1.42 \%$ (119 / 8372) of patients were noted to have allergic reactions after injection of isosulfan blue compared with $0.86 \%(68 / 7917)$ of patients recruited in the NEW START and ALMANAC studies (Table 3) (difference $0.56 \%$, 95\% CI 0.24 to 0.89). Severe allergic reactions with hypotension requiring treatment with vasoactive drugs (grade III allergic reaction) were noted in $0.44 \%$ (37 / 8372) of patients after injection of isosulfan compared with $0.06 \%(5 / 7917)$ of patients who received patent blue V (Table 3) (difference $0.38 \%$, $95 \%$ CI 0.23 to 0.55 ). 


\section{Discussion}

The combination of isotope and blue dye is the current recommended technique for sentinel node localisation in breast cancer in the UK with localisation rates of over 99\%. However, blue dye is associated with a range of allergic reactions. There have been a number of case reports and single case series of anaphylactic reactions following administration of patent blue V. Its allergic potential is also reflected in reports to the Committee of Safety of Medicines and to the manufacturer. No mortality has been reported but two cardio-respiratory arrests have been attributed to patent blue $\mathrm{V}^{5,6}$. This is the first prospective analysis of anaphylactic reactions of patent blue $\mathrm{V}$ dye in a large cohort. The allergic risk of patent blue $\mathrm{V}$ compares favourably with the published US data on isosulfan blue.

\section{Predicted incidence of blue dye reactions in UK}

Severe potentially life threatening allergic reactions are rare but the total number of adverse reactions will rise with increasing use of sentinel lymph node biopsy in the UK. NICE (National Institute of Clinical Excellence, UK) 2009 guidelines recommend that axillary staging should be performed by sentinel lymph node biopsy using a combination of isotope and blue dye. ${ }^{7}$ Breast cancer is the most common cancer affecting women in England and Wales, with about 44,000 new cases diagnosed each year. ${ }^{8,9}$ Approximately 25,000 - 30,000 of these patients with early stage breast cancer will undergo axillary staging by sentinel node biopsy. Based on the risk of reaction from the NEW START and ALMANAC dataset, 15 to 18 patients (0.06 \%) may suffer severe grade 3 allergic reactions per annum.

It is not possible to accurately foresee anaphylaxis in a particular patient as severe allergic reactions to patent blue $\mathrm{V}$ have occurred in patients without any allergic 
predisposition. ${ }^{6}$ Pre-operative antiallergic medication does not prevent anaphylactic reactions but can reduce severity. ${ }^{10}$

Omitting patent blue $V$ increases the false-negative rate

In an effort to minimise blue dye morbidity some centres are now performing isotope only localisation. We have some concerns with regards to this: in the ALMANAC validation phase in $10 \%$ of patients the sentinel lymph node stained with blue dye, but did not take up ${ }^{99 \mathrm{~m}} \mathrm{Tc}$-albumin colloid. More importantly, in approximately $4 \%$ patients, the sentinel node that was involved with metastatic disease was identified by blue dye alone. $^{11}$

An attractive option is to use blue dye selectively in the subgroup of patients in whom a hot node is not demonstrated on the lymphoscintiscan or cannot be detected with a gamma-probe. However, there is no published data on how this approach will influence the false-negative rate. NEW START dataset analyses will be able to answer this question, however till this is done all teams should use a combined technique (isotope and blue dye) for sentinel node localisation.

Methylene blue

Methylene blue dye due to its lower cost, lower allergic potential and lesser interference with pulse oximetry ${ }^{12,13}$ has been used as an alternative. Sentinel lymph node detection rates with methylene blue are similar to isosulfan blue $e^{14-18}$ despite theoretical concerns about its poor lymphatic uptake due to its lack of sulfonic acid groups essential for binding to plasma proteins and absorption into lymphatics ${ }^{19}$. However, it is associated with fat necrosis ${ }^{20-22}$ and capsular contraction after implant surgery. ${ }^{23}$ While its allergic potential is less as reflected in fewer reports in the published literature and to the Committee of Safety of Medicines it is by no means non-existent. ${ }^{24,25}$ 
Anaesthesia related anaphylaxis

Anaesthesia related anaphylaxis has been estimated at between 1 in $10,000-20,000{ }^{26}$ Neuromuscular blocking drugs are the commonest cause of anaesthesia related reactions. Other causes are latex hypersensitivity, antibiotics, local anaesthetics, anaesthetic induction agents, antiseptics, opioids, NSAIDs and colloids. It can be difficult to recognize the causative factor in any allergic reaction in patients undergoing blue dye guided sentinel node biopsy during general anaesthesia. However, the presence of blue hives is diagnostic of reaction to the blue dye.

\section{Practice guidelines}

We recommend that allergic risk should be documented and discussed with patients undergoing sentinel lymph node biopsy when taking consent. Patent blue V should be avoided in patients with an allergy history to foods containing food colorant E 131 or hyperallergic patients carrying an adrenaline-containing syringe for selfadministration (epipen ${ }^{\circledR}$ ). However, omitting blue dye may adversely affect the failed localisation and false-negative rates.

The surgeon should verbally alert the anaesthetist when patent blue V dye is administered. Since the use of patent blue V dye is on a named basis only and a licence is unlikely to be issued in future, we encourage reporting of adverse effects of patent blue V dye to the Committee of Safety of Medicines with the Yellow Card System in the UK.

\section{Conclusion}

The allergic potential of patent blue V dye compares favourably with isosulfan blue. Severe anaphylaxis is rare. However, surgical and anaesthetic teams need to be alert to the risk of allergic reactions. 


\section{Acknowledgements}

We thank all patients who participated in the NEW START training programme and ALMANAC trial; other study investigators; research fellows and all the surgery, nuclear medicine, radiological, radiographic, and nursing staff at each centre.

\section{Conflict of interest}

None. 
Reference List

1. Scherer K, Bircher AJ, Figueiredo V. Blue Dyes in Medicine--a Confusing Terminology. Contact Dermatitis 2006; 54(4): 231-2.

2. Kalimo K, Jansen CT, Kormano M. Sensitivity to Patent Blue Dye During Skin-Prick Testing and Lymphography. A Retrospective and Prospective Study. Radiology 1981; 141(2): 365-7.

3. Mansel RE, Fallowfield L, Kissin M, Goyal A, Newcombe RG, Dixon JM, Yiangou C, Horgan K, Bundred N, Monypenny I, England D, Sibbering M, Abdullah TI, Barr L, Chetty U, Sinnett DH, Fleissig A, Clarke D, Ell PJ. Randomized Multicenter Trial of Sentinel Node Biopsy Versus Standard Axillary Treatment in Operable Breast Cancer: the ALMANAC Trial. J Natl Cancer Inst 2006; 98(9): 599-609.

4. Montgomery LL, Thorne AC, Van Zee KJ, Fey J, Heerdt AS, Gemignani M, Port E, Petrek J, Cody HS, III, Borgen PI. Isosulfan Blue Dye Reactions During Sentinel Lymph Node Mapping for Breast Cancer. Anesth Analg 2002; 95(2): 385-8, table.

5.

Http://Www.Mhra.Gov.Uk/Home/Groups/Public/Documents/Sentineld ocuments/Dap_1233148728979.Pdf. Accessibility checked on 28/02/09.

6. Wohrl S, Focke M, Hinterhuber G, Stingl G, Binder M. Near-Fatal Anaphylaxis to Patent Blue V. Br J Dermatol 2004; 150(5): 1037-8.

7. Http://Www.Nice.Org.Uk/Guidance/CG80. Accessibility checked on 28/02/09.

8. Welsh Cancer Intelligence and Surveillance Unit (2008) Cancer Incidence in Wales 1992-2002. Cardiff: Welsh Cancer Intelligence and Surveillance Unit 2009.

9. Office for National Statistics (2008) Cancer Statistics Registrations:

Registrations of Cancer Diagnosed in 2005, England. Series MB1 number 36 London: Office for National Statistics 2009.

10. Raut CP, Hunt KK, Akins JS, Daley MD, Ross MI, Singletary SE, Marshall GD, Jr., Meric-Bernstam F, Babiera G, Feig BW, Ames FC, Kuerer HM. Incidence of Anaphylactoid Reactions to Isosulfan Blue Dye During Breast Carcinoma Lymphatic Mapping in Patients Treated With Preoperative Prophylaxis: Results of a Surgical Prospective Clinical Practice Protocol. Cancer 2005; 104(4): 692-9.

11. Goyal A, Newcombe RG, Chhabra A, Mansel RE. Factors Affecting Failed Localisation and False-Negative Rates of Sentinel Node Biopsy in Breast Cancer--Results of the ALMANAC Validation Phase. Breast Cancer Res Treat 2006; 99(2): 203-8. 
12. Aydogan F, Celik V, Uras C, Salihoglu Z, Topuz U. A Comparison of the Adverse Reactions Associated With Isosulfan Blue Versus Methylene Blue Dye in Sentinel Lymph Node Biopsy for Breast Cancer. Am J Surg 2008; 195(2): 277-8.

13. Pinero A, Illana J, Garcia-Palenciano C, Canizarese F, Canteras M, Canadillas V, Duran E, Parilla P. Effect on Oximetry of Dyes Used for Sentinel Lymph Node Biopsy. Arch Surg 2004; 139(11): 1204-7.

14. Golshan M, Nakhlis F. Can Methylene Blue Only Be Used in Sentinel Lymph Node Biopsy for Breast Cancer? Breast J 2006; 12(5): 428-30.

15. Varghese P, Abdel-Rahman AT, Akberali S, Mostafa A, Gattuso JM, Carpenter R. Methylene Blue Dye--a Safe and Effective Alternative for Sentinel Lymph Node Localization. Breast J 2008; 14(1): 61-7.

16. Nour A. Efficacy of Methylene Blue Dye in Localization of Sentinel Lymph Node in Breast Cancer Patients. Breast J 2004; 10(5): 388-91.

17. Simmons RM, Smith SM, Osborne MP. Methylene Blue Dye As an Alternative to Isosulfan Blue Dye for Sentinel Lymph Node Localization. Breast J 2001; 7(3): 181-3.

18. Blessing WD, Stolier AJ, Teng SC, Bolton JS, Fuhrman GM. A Comparison of Methylene Blue and Lymphazurin in Breast Cancer Sentinel Node Mapping. Am J Surg 2002; 184(4): 341-5.

19. Tsopelas C, Sutton R. Why Certain Dyes Are Useful for Localizing the Sentinel Lymph Node. J Nucl Med 2002; 43(10): 1377-82.

20. Salhab M, Al Sarakbi W, Mokbel K. Skin and Fat Necrosis of the Breast Following Methylene Blue Dye Injection for Sentinel Node Biopsy in a Patient With Breast Cancer. Int Semin Surg Oncol 2005; 2: 26.

21. Ruhlen JL. Tissue Necrosis. Cutaneous and Subcutaneous Damage Following Extravasation of Methylene Blue. J Kans Med Soc 1982; 83(5): 236, 260.

22. Perry PM, Meinhard E. Nectotic Subcutaneous Abscesses Following Injections of Methylene Blue. Br J Clin Pract 1974; 28(8): 289-91.

23. Singh-Ranger G, Mokbel K. Capsular Contraction Following Immediate Reconstructive Surgery for Breast Cancer - An Association With Methylene Blue Dye. Int Semin Surg Oncol 2004; 1(1): 3.

24. Dewachter P, Mouton-Faivre C, Trechot P, Lleu JC, Mertes PM. Severe Anaphylactic Shock With Methylene Blue Instillation. Anesth Analg 2005; 101(1): 149-50, table.

25. Rzymski P, Wozniak J, Opala T, Wilczak M, Sajdak S. Anaphylactic Reaction to Methylene Blue Dye After Laparoscopic Chromopertubation. Int J Gynaecol Obstet 2003; 81(1): 71-2. 
26. Laxenaire MC. [Epidemiology of Anesthetic Anaphylactoid Reactions. Fourth Multicenter Survey (July 1994-December 1996)]. Ann Fr Anesth Reanim 1999; 18(7): 796-809.

27. Leong SP, Donegan E, Heffernon W, Dean S, Katz JA. Adverse Reactions to Isosulfan Blue During Selective Sentinel Lymph Node Dissection in Melanoma. Ann Surg Oncol 2000; 7(5): 361-6.

28. Albo D, Wayne JD, Hunt KK, Rahlfs TF, Singletary SE, Ames FC, Feig BW, Ross MI, Kuerer HM. Anaphylactic Reactions to Isosulfan Blue Dye During Sentinel Lymph Node Biopsy for Breast Cancer. Am J Surg 2001; 182(4): 393-8.

29. Cimmino VM, Brown AC, Szocik JF, Pass HA, Moline S, De SK, Domino EF. Allergic Reactions to Isosulfan Blue During Sentinel Node Biopsy--a Common Event. Surgery 2001; 130(3): 439-42.

30. King TA, Fey JV, Van Zee KJ, Heerdt AS, Gemignani ML, Port ER, Sclafani L, Sacchini V, Petrek JA, Cody HS, III, Borgen PI, Montgomery LL. A Prospective Analysis of the Effect of Blue-Dye Volume on Sentinel Lymph Node Mapping Success and Incidence of Allergic Reaction in Patients With Breast Cancer. Ann Surg Oncol 2004; 11(5): 535-41.

31. Daley MD, Norman PH, Leak JA, Nguyen DT, Bui TP, Kowalski AM, Srejic U, Popat K, Arens JF, Gershenwald JE, Hunt KK, Kuerer HM. Adverse Events Associated With the Intraoperative Injection of Isosulfan Blue. J Clin Anesth 2004; 16(5): 332-41.

32. Komenaka IK, Bauer VP, Schnabel FR, Horowitz E, Joseph KA, Ditkoff BA, El Tamer MB. Allergic Reactions to Isosulfan Blue in Sentinel Lymph Node Mapping. Breast J 2005; 11(1): 70-2. 
Table 1. Adverse reactions to patent blue V dye

\begin{tabular}{lll}
\hline Study & $\begin{array}{l}\text { Adverse reactions } \\
\text { patent blue V dye }\end{array}$ & $\begin{array}{l}\text { 95\% confidence } \\
\text { interval }\end{array}$ \\
\hline $\begin{array}{l}\text { NEW START } \\
(n=6586)\end{array}$ & $0.9 \%(58 / 6586)$ & $0.7 \%-1.1 \%$ \\
$\begin{array}{l}\text { ALMANAC } \\
\text { randomised phase } \\
(n=492)\end{array}$ & $1.0 \%(5 / 492)$ & $0.4 \%-2.4 \%$ \\
$\begin{array}{l}\text { ALMANAC validation } \\
\text { phase } \\
(n=839)\end{array}$ & $1.1 \%(9 / 839)$ & $0.6 \%-2.0 \%$ \\
\hline Total $(n=7917)$ & $0.9 \%(72 / 7917)$ & $0.7 \%-1.1 \%$ \\
\hline
\end{tabular}


Table 2. Side-effects of patent blue V dye

\begin{tabular}{|l|l|l|}
\hline Allergic reactions & 23 patients \\
\hline Grade I & urticaria, blue hives, pruritis, or generalised rash & \\
\hline Grade II & transient hypotension/ bronchospasm /laryngospasm & 16 patients \\
\hline Grade III & $\begin{array}{l}\text { severe hypotension (requiring vasopressor support) } \\
\text { and/or change / abandoning of planned procedure } \\
\text { and/or HDU/ITU admission }\end{array}$ & 5 patients \\
\hline Grade IV & cardio-respiratory arrest and/or death & - \\
\hline Unspecified & 24 patients \\
\hline Total allergic reactions & 68 \\
\hline Non-allergic reactions & 1 patient \\
\hline $\begin{array}{l}\text { Skin tattooing } \\
\text { Bluish hue persisting for few hours }\end{array}$ & 3 patients \\
\hline Total allergic + non-allergic reactions & 72 \\
\hline
\end{tabular}


Table 3. Allergic reactions to isosulfan blue compared to patent blue $\mathrm{V}$ dye

\begin{tabular}{|c|c|c|c|c|}
\hline Author & $\begin{array}{l}\text { No. of } \\
\text { patients }\end{array}$ & Agent & Allergic reaction & $\begin{array}{l}\text { Grade III } \\
\text { reaction }\end{array}$ \\
\hline Leong SP $2000^{27}$ & 406 & Isosulfan blue & $3 / 406$ (0.7\%) & $3 / 406(0.7 \%)$ \\
\hline Albo D $2001^{28}$ & 639 & Isosulfan blue & 7 / 639 (1.1\%) & 7 / 639 (1.1\%) \\
\hline $\begin{array}{l}\text { Cimmino VM } \\
2001^{29}\end{array}$ & 267 & Isosulfan blue & 5 / $267(2 \%)$ & $2 / 267$ (0.7\%) \\
\hline $\begin{array}{l}\text { Blessing WD } \\
2002^{18}\end{array}$ & 87 & Isosulfan blue & 0 & 0 \\
\hline $\begin{array}{l}\text { Montgomery LL } \\
2002^{4}\end{array}$ & 2392 & Isosulfan blue & 39 / 2392 (1.6 \%) & 9 / $2392(0.4 \%)$ \\
\hline King TA $2004^{30}$ & 1728 & Isosulfan blue & 31 / 1728 (1.8 \%) & 2 / 1728 (0.1\%) \\
\hline Daley MD $2004^{31}$ & 1835 & Isosulfan blue & 28 / $1835(1.5 \%)$ & $\begin{array}{llll}14 & 1835(0.75 \\
\%) & & \end{array}$ \\
\hline $\begin{array}{l}\text { Komenaka IK } \\
2005^{32}\end{array}$ & 351 & Isosulfan blue & 3 / 351 (0.9 \%) & 0 \\
\hline Raut CP $2005^{11}$ & 667 & Isosulfan blue & $3 / 667(0.4 \%)$ & 0 \\
\hline Others total & 8372 & Isosulfan blue & 119 / $8372(1.4 \%)$ & 37 / 8372 (0.4 \%) \\
\hline $\begin{array}{l}\text { NEW START + } \\
\text { ALMANAC }\end{array}$ & 7917 & Patent blue $\mathrm{V}$ & 68 / 7917 (0.9 \%) & 5 / 7917 (0.06 \%) \\
\hline
\end{tabular}

